\title{
Fatores de Influência do PIB per capita dos Estados Brasileiros: uma Análise de Painel com o Uso dos Métodos PCSE e FGLS (1991-2009)
}

\section{Influential Factors of Brazilian States' GDP per capita: a Panel Data Analysis through PCSE and FGLS Methods (1991-2009)}

\author{
Italo Spinelli da Cruz* \\ Fábio Rodrigues de Moura** \\ José Ricardo de Santana*** \\ Luiz Carlos de Santana Ribeiro****
}

Resumo: Este trabalho tem como objetivo avaliar a significância de um conjunto de variáveis econômicas, sociais e de capital humano, encontradas na literatura, como fatores de influência do PIB per capita dos estados brasileiros entre os anos de 1991 e 2009. Para tanto, estima-se um painel de dados por meio do método Feasible Generalized Least Squares (FGLS), proposto por Parks (1967), e do método Panel Corrected Standard Errors (PCSE), desenvolvido por Beck e Katz (1995). Os métodos FGLS e PCSE produzem boas estimativas para os coeficientes, sendo todos significativos estatisticamente e com sinal esperado. Os resultados encontrados corroboram os achados da literatura.

Palavras-chave: Fatores de influência do PIB per capita. FGLS. PCSE.

\begin{abstract}
This paper aims to assess the significance of a set of economic, social and human capital variables found in the literature as influencing factors of Brazilian states' GDP per capita between 1991 and 2009. In this regard, we estimated a panel data by the method of Feasible Generalized Least Squares (FGLS), proposed by Parks (1967) and the method of Panel Corrected Standard Errors (PCSE), developed by Beck and Katz (1995). The FGLS and PCSE methods produced good estimates for the coefficients, being all statistically significant and with expected sign. The results corroborate the findings of the literature.
\end{abstract}

Keywords: Influence factors of per capita GDP. FGLS. PCSE.

JEL Classification: C23; O47.

* $\quad$ Mestre em Desenvolvimento Regional pelo Núcleo de Pós-Graduação e Pesquisa em Economia (Nupec) da Universidade Federal de Sergipe (UFS). E-mail: italo.spinelli@gmail.com

** Doutorando em Economia Aplicada pela Escola Superior de Agricultura "Luiz de Queiroz" (Esalq) da Universidade de São Paulo (USP). E-mail: fabirosmash@yahoo.com.br

** * Doutor em Economia de Empresas pela Fundação Getúlio Vargas (FGV/SP). Professor associado do Departamento de Economia da Universidade Federal de Sergipe (UFS). E-mail: santana josericardo@yahoo.com.br

**** Doutorando em Economia pelo Centro de Desenvolvimento e Planejamento Regional (Cedeplar) da Universidade Federal de Minas gerais (UFMG).E-mail: luizribeiro@cedeplar.ufmg.br 


\section{1 lntrodução}

Nas duas últimas décadas, apesar da retomada do crescimento econômico no Brasil, ainda se observam diferenças elevadas nos PIBs per capita das regiões (BARROS, 2011). Estudos recentes (MONASTÉRIO; ÁVILA, 2004; SILVEIRA NETO; AZZONI, 2006; GONDIM; BARRETO; CARVALHO, 2007; FERRARIO et al., 2009; RESENDE, 2011; RIBEIRO; ALMEIDA, 2012) buscam identificar o padrão de crescimento das regiões, estados ou municípios brasileiros, analisando, a partir de um conjunto de variáveis, se há ou não tendência de convergência da renda entre os estados brasileiros.

Nessa linha mostra-se importante ainda a necessidade de investigar os fatores que podem influenciar o crescimento econômico dos estados brasileiros. O presente trabalho tem por objetivo avaliar empiricamente os fatores de influência no desempenho do PIB per capita dos estados brasileiros.

Foi proposto um modelo que traz alguns desses principais fatores, como população e capital humano, apresentados pela literatura teórica, além de esperança de vida, economias de aglomeração, peso do Estado e peso dos setores de atividade, baseados no que traz a literatura empírica. Desse modo, trabalha-se com a hipótese de que a taxa de crescimento populacional, a média de anos de estudo, a esperança de vida da população, a taxa de urbanização, o peso dos tributos e as taxas de crescimento dos setores industrial, agropecuário e de serviços são fatores que exercem influência no PIB per capita dos estados.

Para avaliar o impacto dessas variáveis sobre o PIB per capita, especificou-se um modelo econométrico para o painel de dados, composto pelas variáveis mencionadas para as 27 unidades da federação (UF) entre os anos de 1991 e 2009. A estimação envolveu o trabalho com modelos de painel com efeitos fixos e com efeitos aleatórios. Os testes utilizados apontaram para a presença de distúrbios não esféricos no modelo especificado. Desse modo, justifica-se a estimação por meio dos métodos feasible generalized least squares (FGLS) e panel-corrected standard errors (PCSE), comparando-os também com as estimativas de efeitos fixos e aleatórios.

As principais contribuições deste trabalho baseiam-se na estimação de um modelo em painel de dados, a partir dos principais fatores apontados pela literatura, para um período relativamente longo e recente da economia brasileira (1991-2009), por meio dos métodos FGLS e, sobretudo, do PCSE. Esses modelos mostram-se consistentes em detrimento das estimações por efeitos fixos ou aleatórios quando há presença de distúrbios não esféricos.

Além dessa introdução, o trabalho é composto de mais quatro seções. Na segunda seção apresenta-se a literatura empírica que avalia os determinantes do crescimento econômico para o caso brasileiro. Em seguida, na terceira seção, são 
apresentadas algumas informações descritivas sobre a evolução socioeconômica dos estados no período analisado. A quarta seção trata dos aspectos metodológicos, mostrando os dados utilizados e o modelo econométrico proposto para a análise empírica, e apresenta a discussão dos resultados obtidos. A quinta seção traz as considerações finais.

\section{Fatores de Influência do Crescimento Econômico: Referencial Teórico e Estudos Aplicados ao Caso Brasileiro}

O empenho dos pesquisadores da temática regional em entender os fatores que influenciam as desigualdades de renda entre as regiões brasileiras ganhou destaque nas últimas décadas. Grande parte desses estudos analisa principalmente a hipótese de convergência (ou não) entre as rendas per capita estaduais ou regionais brasileiras. Este trabalho, entretanto, busca identificar possíveis variáveis que influenciam os diferenciais de renda nos estados brasileiros, tomando como base fatores apontados na literatura teórica e empírica sobre o assunto.

Barro e Sala-i-Martin (2003) indicam o modelo desenvolvido por Solow (1956) como o que apresentou contribuições mais importantes para a então moderna teoria do crescimento. Em Solow (1956) são as taxas de poupança e crescimento populacional, considerados fatores exógenos, que especificam o nível de renda per capita de longo prazo. Em linhas gerais, o crescimento populacional afeta negativamente o crescimento do PIB per capita.

Um fator específico de investigação que merece destaque nesse debate é o capital humano, já consolidado como fator relevante nas análises de crescimento econômico, como apresentado em Lucas Jr. (1988) e Mankiw, Romer e Weil (1992). Segundo Barro (1996), os países que mais cresceram entre 1965-1990 foram os que apresentaram elevada escolaridade secundária. Em relação a trabalhos aplicados ao Brasil, Lau et al. (1993) estimaram um modelo cross-section para os estados brasileiros nos anos 1970 e 1980, verificando a relação entre anos de estudos da força de trabalho e o crescimento do produto estadual. Os resultados mostraram que, para um aumento de um ano médio nos anos de estudo, haveria um aumento de $20 \%$ no produto estadual brasileiro. A relação entre a escolaridade e o crescimento econômico estadual também é verificada por Souza (1999). Os resultados indicaram que, com a inclusão do capital humano, o modelo tende a ser mais explicativo, mostrando assim a influência da variável escolaridade nas variações do crescimento do PIB.

Outra maneira de avaliar a importância do capital humano para o crescimento econômico é a partir da inserção de uma proxy que identifique a influência do estado de saúde da população sobre o crescimento. Barro (1996) afirma que países com alta expectativa de vida cresceram mais em termo per capita, o que 
ressalta a importância do capital humano no produto per capita dos países. Para o caso brasileiro, Figueiredo, Noronha e Andrade (2003) apontaram que a saúde influencia positivamente o crescimento econômico dos estados. Entre as variáveis utilizadas para analisar essa relação, os autores indicaram a taxa de mortalidade infantil e a taxa de fecundidade. Os resultados apontaram que regiões com menor provimento de saúde teriam um nível de renda per capita inferior no longo prazo.

Entre os estudos empíricos, com abordagem de economia regional, os trabalhos de Azzoni et al. (2000) e Resende e Figueiredo (2005) são os que apresentam de forma mais abrangente um conjunto de possíveis indicadores. Resende e Figueiredo (2005) buscaram entender quais variáveis possuem uma correlação robusta com as taxas de crescimento do PIB per capita dos estados brasileiros para o período de 1960 a 2000. Os resultados apontam que as taxas de urbanização, mortalidade infantil, fecundidade, pluviometria, carga tributária e migração apresentaram uma correlação robusta com as taxas de crescimento do PIB per capita dos estados brasileiros. Azzoni et al. (2000), por sua vez, analisaram os impactos das variáveis geográficas (entre elas, urbanização, expectativa de vida e taxa de mortalidade infantil) nas variações do crescimento do PIB per capita dos estados brasileiros no período de 1981 a 1996. Os resultados indicaram uma forte influência das variáveis geográficas nas diferenciações do padrão e no crescimento da renda dos estados.

Outros fatores pontuais são destacados na literatura empírica, como o papel do Estado no crescimento econômico (ROMER, 1986; LUCAS JR., 1988; BARRO, 1996, 1991). Arraes e Teles (2001) investigaram o desempenho dos governos estaduais no período de 1981 a 1995, verificando quais estados encontravam-se acima do nível da carga tributária considerada ideal, já que os estados brasileiros apresentavam governos muito grandes, o que causaria um efeito negativo sobre o crescimento. No entanto, os resultados também apontaram que os gastos produtivos dos governos em transporte e infraestrutura, bem como em educação e cultura geraram um efeito positivo sobre o crescimento. Llédo (1996), por sua vez, verificou através de um cross-section para os estados brasileiros como a distribuição da renda e a política fiscal se relacionaram, no decorrer das décadas de 70 e 80 , com as taxas de crescimento da renda per capita. Os resultados encontrados indicaram a existência de uma relação em " $U$ " invertido entre carga tributária e variações na renda per capita.

Alguns trabalhos aplicados para as regiões brasileiras apresentam ainda abordagens da nova geografia econômica. Menezes e Ferreira Jr. (2003) analisaram de que maneira a mobilidade do fator trabalho influenciava na velocidade de convergência de renda entre os estados brasileiros no período de 1992 a 1999. Os resultados indicaram que os fluxos migratórios contribuíram para um aumento das desigualdades de rendas entre os estados. Já Oliveira (2004), num estudo para 
as cidades nordestinas na década de 90, destacou a importância do fluxo migratório do capital humano e da urbanização no crescimento. Para o autor, cidades mais urbanizadas apresentaram um maior grau de crescimento, que é associado à concentração de pessoas com maior nível de capital humano, o que permite uma transferência de conhecimento e difusão de tecnologias.

Por fim, Ferreira e Diniz (1995), ao considerarem a estrutura produtiva de cada estado e a importância que cada setor da atividade econômica exerce no crescimento da renda, apontaram uma tendência à convergência das rendas per capita estaduais e regionais no período de 1970 a 1985, ocasionada por mudanças no padrão locacional dos setores industrial, extrativista e agropecuário, e os efeitos destas sobre os serviços urbanos. Azzoni (1997) buscou caracterizar a concentração da estrutura produtiva brasileira ao calcular a importância de cada setor da atividade econômica no crescimento e na dispersão da renda per capita dos estados e regiões no período de 1939 a 1995. O autor identificou uma redução na desigualdade intrarregional, acompanhada, entretanto, de um aumento das desigualdades inter-regionais. Mais recentemente Amorim, Scalco e Braga (2008), no intuito de analisar o nível da renda per capita dos estados no período de 1980 a 2000, examinaram as variações ocorridas no PIB per capita tanto em sua forma agregada quanto em sua decomposição nos três grandes setores: agropecuário, industrial e de serviços. O modelo evidenciou a existência de convergência da renda tanto para o nível agregado quanto para os setores da indústria e serviços.

Isso mostra o conjunto considerável de fatores de influência que podem ser identificados na literatura sobre o assunto. O desafio é investigar, a partir dos grupos de fatores apontados pela literatura teórica e empírica, quais variáveis podem influenciar de forma significativa o PIB per capita dos estados, de modo a auxiliar a explicação das desigualdades da renda no Brasil. A próxima seção mostra uma análise descritiva das principais variáveis a serem utilizados no modelo proposto neste trabalho.

\section{Diferenciais nas Trajetórias de Crescimento e Evolução Socioeconômica dos Estados Brasileiros}

A configuração das desigualdades regionais e das diferentes tendências de crescimento entre os estados brasileiros pode ser ilustrada a partir do comportamento de algumas variáveis utilizadas neste trabalho. Foi considerada a abrangência da amostra utilizada no estudo empírico, que compreende o período entre 1991 e 2009.

Ao longo dos quase vinte anos analisados neste estudo, o PIB brasileiro apresentou um crescimento médio de aproximadamente 3,0\%. Essa tendência de crescimento foi registrada em todas as UF, como pode ser observado no Gráfico 1. 
No entanto, a trajetória da evolução do PIB nos estados e no Brasil apresentou variações bem distintas no decorrer do mesmo período. Para o país, o crescimento médio do PIB per capita ficou em torno de 1,5\% entre 1991 e 2009.

Gráfico 1 - Taxa média de crescimento do PIB dos estados brasileiros e do Brasil (1991-2009)

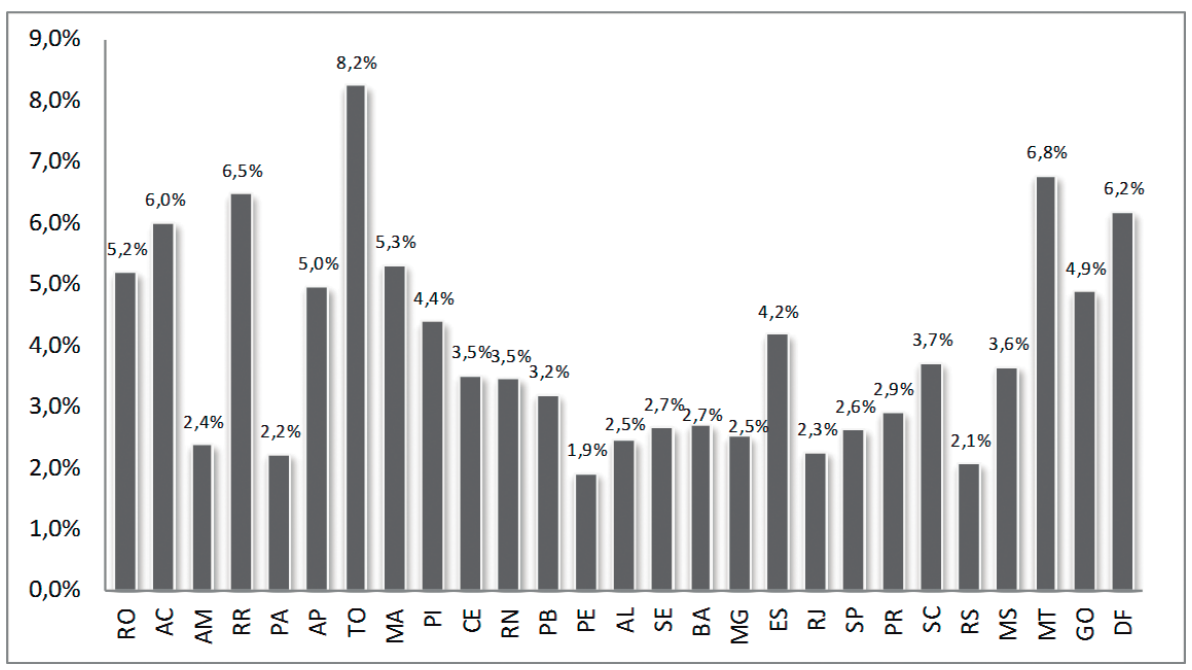

Fonte: Elaboração própria com base nos dados das Contas Regionais de 1991a 2009 (IBGE, 2012).

Como pode ser observado no Gráfico 2, no período em questão não se define claramente um padrão de crescimento do PIB per capita entre os estados brasileiros, evidenciando-se grandes divergências intra e inter-regionais. Na região Norte essas diferenças são notórias, visto que estados relativamente mais importantes, como o Amazonas e o Pará, apresentaram variações muito abaixo da média nacional. Por outro lado, estados com menor tradição econômica, a exemplo de Rondônia, Acre, Roraima e Tocantins, apresentaram uma variação acima da média nacional.

A região Nordeste apresentou uma tendência semelhante à da região Norte, com grande divergência intrarregional da renda. Estados com menor nível de renda no início do período analisado, a exemplo do Maranhão $(R \$ 1.505,95)$ e do Piauí $(\mathrm{R} \$ 1.613,67)$, apresentaram os maiores crescimentos do PIB no Nordeste, apesar de ambos ainda possuírem o menor nível de PIB per capita entre todos os estados brasileiros. Um dado preocupante está relacionado ao estado de Alagoas, que, em 2009, detinha o terceiro menor PIB per capita do Brasil, e, ao longo das quase duas últimas décadas, apresentou um crescimento médio da renda de 1,3\%, inferior à média nacional. 
Gráfico 2 - Taxa média de crescimento do PIB per capita dos estados brasileiros e do Brasil (1991-2009)

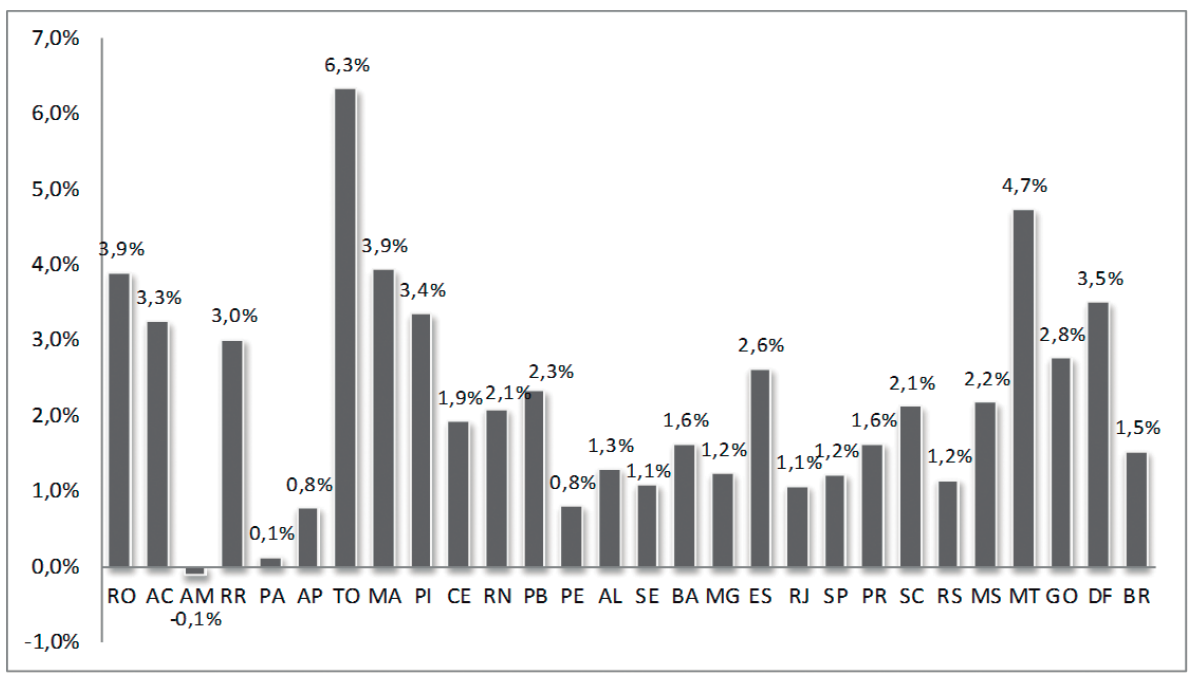

Fonte: Elaboração própria com base nos dados das Contas Regionais de 1991a 2009 (IBGE, 2012).

Com relação ao crescimento da renda nas regiões Sudeste e Sul, que abrange as economias com maior nível do PIB per capita, é possível observar que os estados com maiores níveis de renda no início do período apresentaram um crescimento médio ao longo dos 19 anos menor que o da média brasileira. Para a região Centro-Oeste vale ressaltar os resultados expressivos dos estados que a compõem. Todos apresentaram um crescimento da renda superior à média nacional.

Apesar do crescimento no nível da renda da maioria dos estados mais pobres, ainda é possível observar uma forte desigualdade regional no país. Caso se compare os estados com maior crescimento do PIB per capita nas regióes Norte e Nordeste com o estado de São Paulo, percebe-se o quão díspares são esses padrões de renda. No Nordeste, os estados com maior crescimento do PIB per capita em 2009, Maranhão e Piauí, detinham uma renda de aproximadamente $25 \%$ do valor registrado para o estado de São Paulo. Sergipe, que obteve o maior PIB per capita na região, detinha aproximadamente 50\% do valor encontrado em São Paulo. Esse padrão também foi verificado nos estados da região Norte.

No período analisado, percebe-se uma redefinição nas composições dos setores econômicos em todos os estados brasileiros, como pode ser observado nos Gráficos 3 e 4. As estatísticas apontam uma clara redução na participação do setor industrial na economia de quase todos os estados brasileiros, sendo esse efeito verificado com maior intensidade nas grandes economias brasileiras. O estado de São Paulo, por exemplo, que, em 1991, detinha uma participação de $45 \%$ da in- 
dústria no seu valor adicionado, apresentou, em 2009, uma participação de aproximadamente $29 \%$.

Estados como Santa Catarina, Paraná e Rio Grande do Sul, que, em 1991, apresentavam uma participação do setor industrial superior a 40\%, também revelaram uma forte redução no setor em 2009. Esse decréscimo mais acelerado nas regiões com maior produção industrial pode estar associado à desconcentração produtiva do setor, com uma maior distribuição de indústrias pelas diversas regiões do país, bem como ao processo de abertura comercial da economia brasileira na década de 90. Uma perda significativa também foi evidenciada no estado do Amazonas, que, em 1991, detinha uma participação de 52\% de sua produção em atividades industriais e sofreu uma redução de aproximadamente 15\% em 2009.

Gráfico 3 - Participação dos grandes setores econômicos nos estados brasileiros em 1991

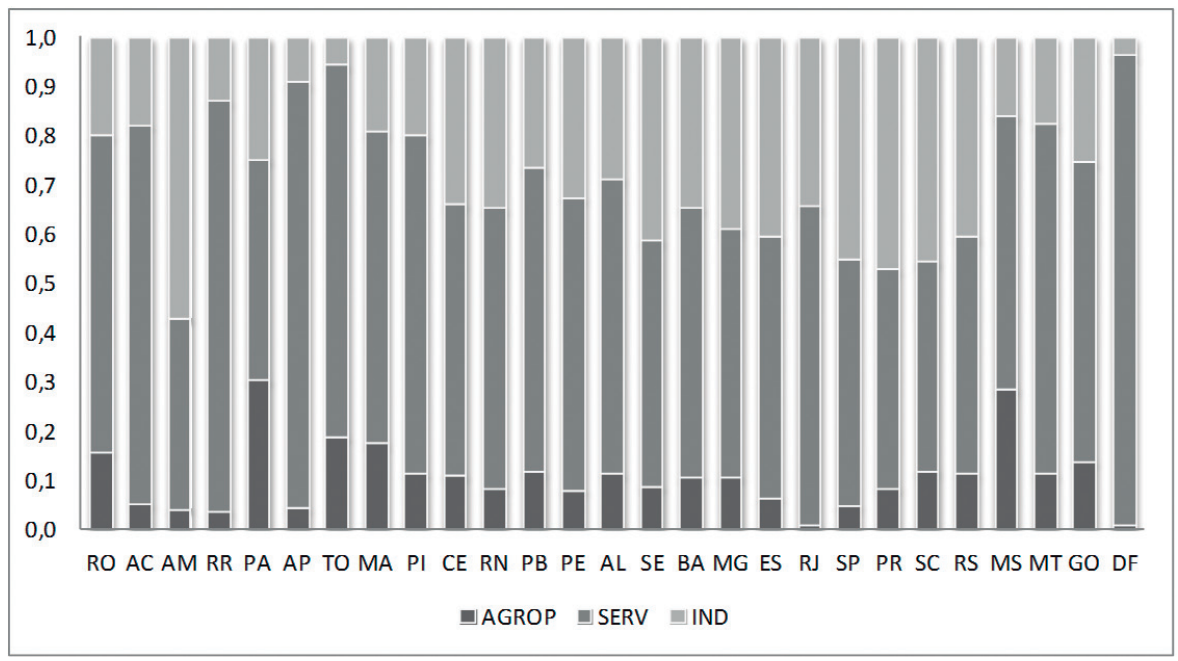

Fonte: Elaboração própria com base nos dados das Contas Regionais de 1991 (IBGE, 2012).

O setor agropecuário é o que tem passado por maiores reduções na composição da estrutura econômica brasileira, comparando-se 1991 e 2009. Em 2009, praticamente todos os estados, com exceção do Acre, Mato Grosso, Mato Grosso do Sul, Rondônia, Goiás e Tocantins, apresentaram uma participação na produção entre $0,5 \%$ e $10 \%$.

O setor de serviços foi o que apresentou uma maior participação no valor adicionado dos estados brasileiros. Em todos os estados, a participação do setor foi superior a 55\% do PIB. O crescimento desse setor está associado a uma reconfiguração espacial da economia brasileira, um maior fluxo migratório para as cidades e um maior grau de urbanização dos estados brasileiros. 
Gráfico 4 - Participação dos grandes setores econômicos nos estados brasileiros em 2009

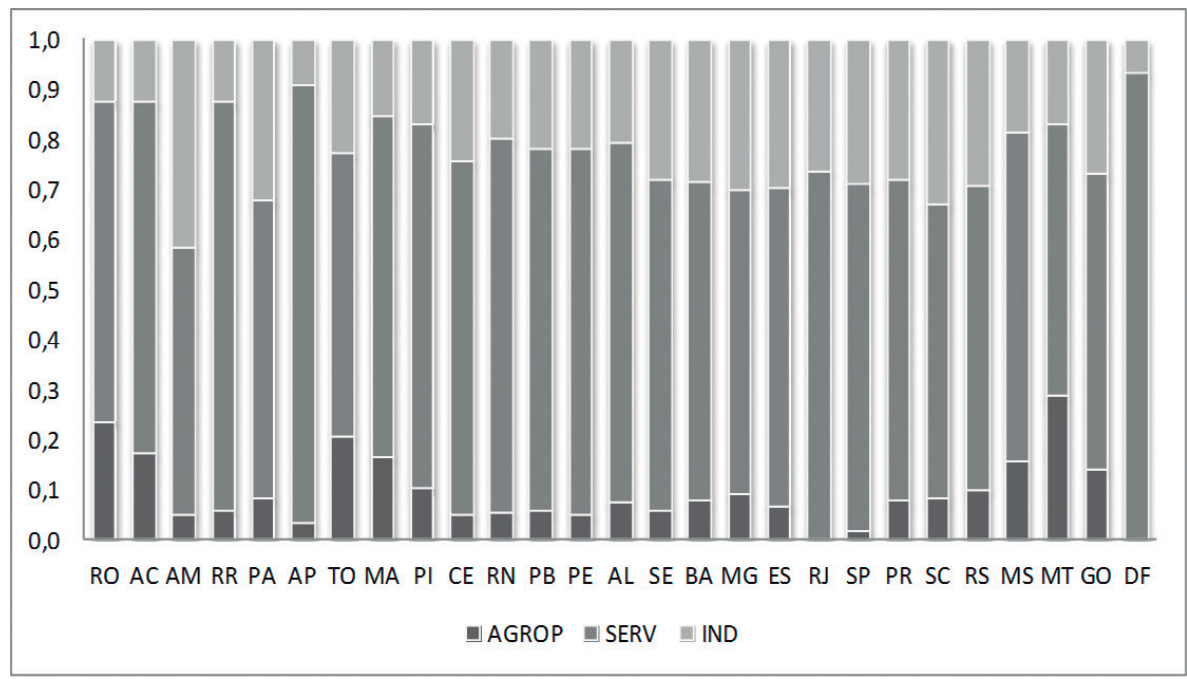

Fonte: Elaboração própria com base nos dados das Contas Regionais de 2009 (IBGE, 2012).

Analisando, ainda, alguns aspectos econômicos, o Gráfico 5 mostra a evolução do peso tributário nos estados brasileiros, cujo resultado indica um aumento significativo da relação entre a arrecadação tributária e o PIB. Os aumentos mais expressivos são vistos nos estados da região Norte e Nordeste, como é o caso do Acre, Amapá e Rio Grande do Norte, que apresentaram um crescimento superior a $100 \%$. Um aumento superior a 50\% é evidenciado ainda no Pará, Paraíba, Pernambuco, Alagoas e Sergipe.

Entre todos os estados, São Paulo $(6,4 \%)$ foi o que apresentou a menor variação no período. Um dado inesperado é a redução na participação da arrecadação em dois estados da região Centro-Oeste, Mato Grosso $(-12,9 \%)$ e Goiás $(-1,4 \%)$. 


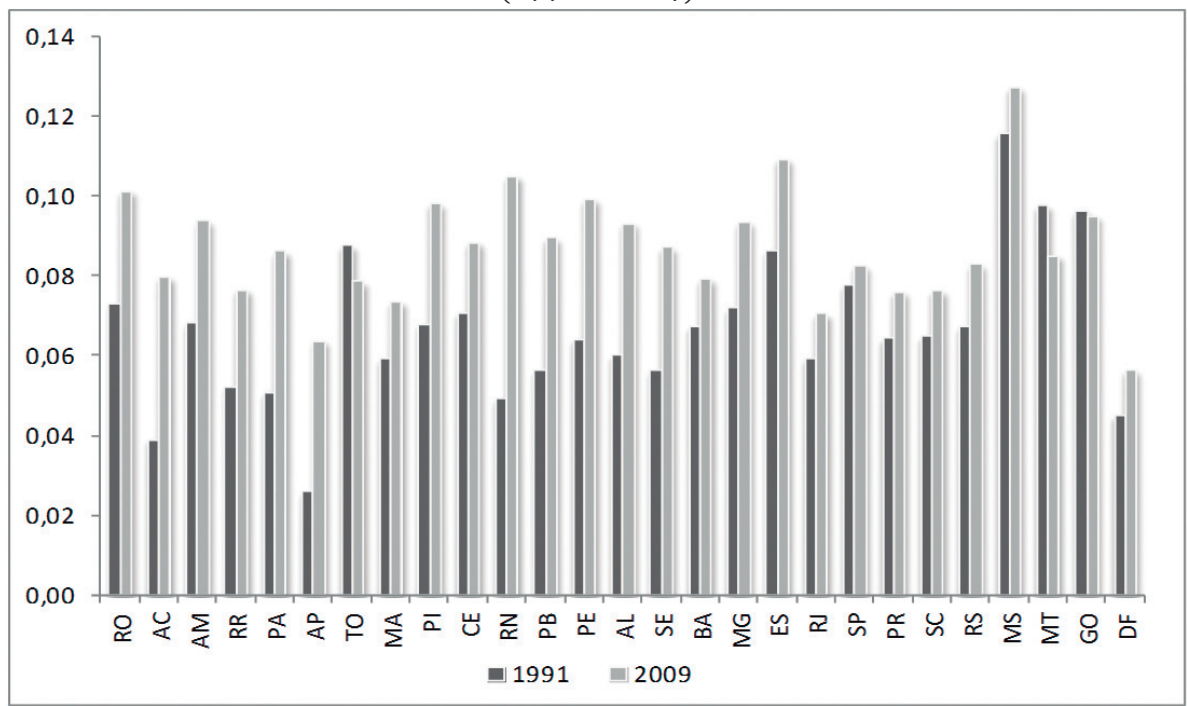

Fontes: Elaboração própria a partir de Brasil (2009, 2012) e IBGE (2012).

Após analisar alguns dos aspectos econômicos relevantes da economia brasileira, é importante verificar como evoluíram outros indicadores apontados, sobretudo na literatura teórica, como fatores importantes para o crescimento de uma região.

Uma observação interessante é a reconfiguração espacial da população, como se pode observar no Gráfico 6. Em todos os estados houve um crescimento da população que vive em zonas urbanas. Esse indicador é fortemente relacionado à ideia das economias de aglomerações apresentadas pela Nova Geografia Econômica (NGE). Observa-se praticamente em todos os estados um percentual superior a 70\% do total da população vivendo na zona urbana, fator fortemente relacionado à expansão do setor de serviços em todos estados brasileiros. 


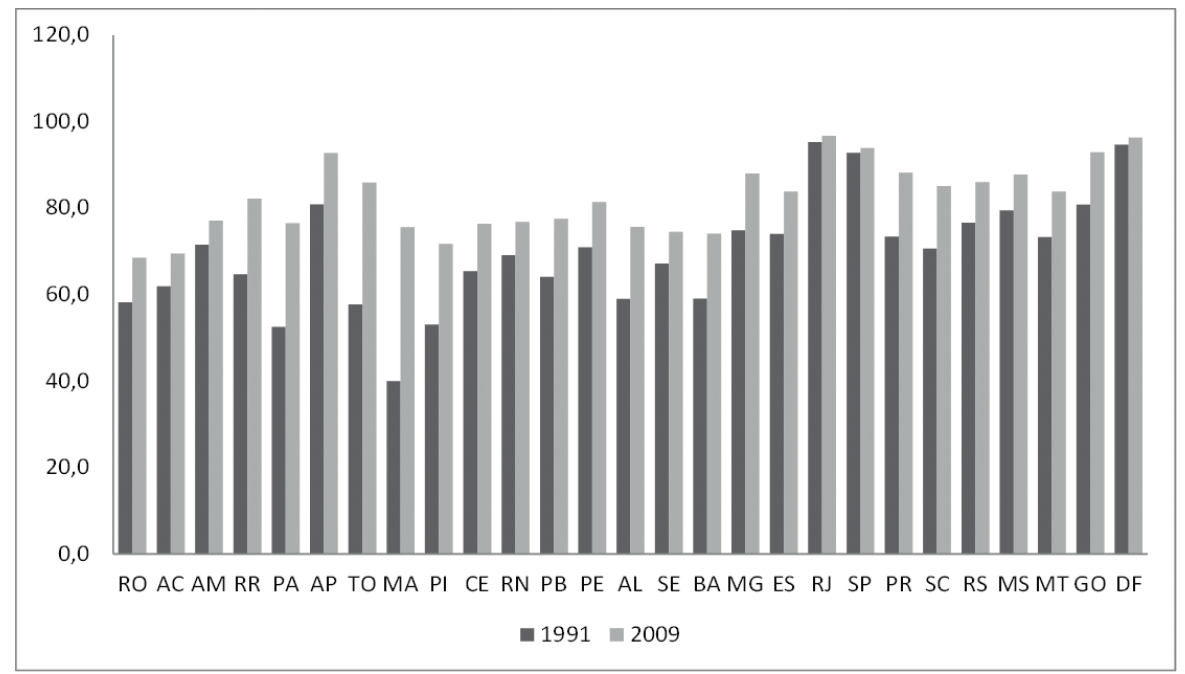

Fonte: Elaboração própria a partir de IBGE $(1991,2009)$.

Outro ponto relevante está associado ao capital humano. Como se pode perceber no Gráfico 7, há uma evolução significativa no nível educacional da população, entretanto ainda há uma diferença considerável entre os estados menos desenvolvidos com relação aos estados com maior PIB per capita. Os piores resultados estão concentrados na região Nordeste do país. Comparando-se os estados com maiores médias de anos de estudos, tais como Distrito Federal $(9,8)$, Rio de Janeiro $(8,1)$ e São Paulo $(7,9)$, aos estados com piores médias, Alagoas $(4,8)$ Piauí $(5,0)$, Paraíba e Maranhão $(5,2)$, pode-se perceber o quão díspar tem sido essa relação, já que a população dos primeiros apresenta aproximadamente entre 3 e 4 anos a mais de estudos. 
Gráfico 7 - Anos médios de estudos da população acima de 25 anos (1991 e 2007)

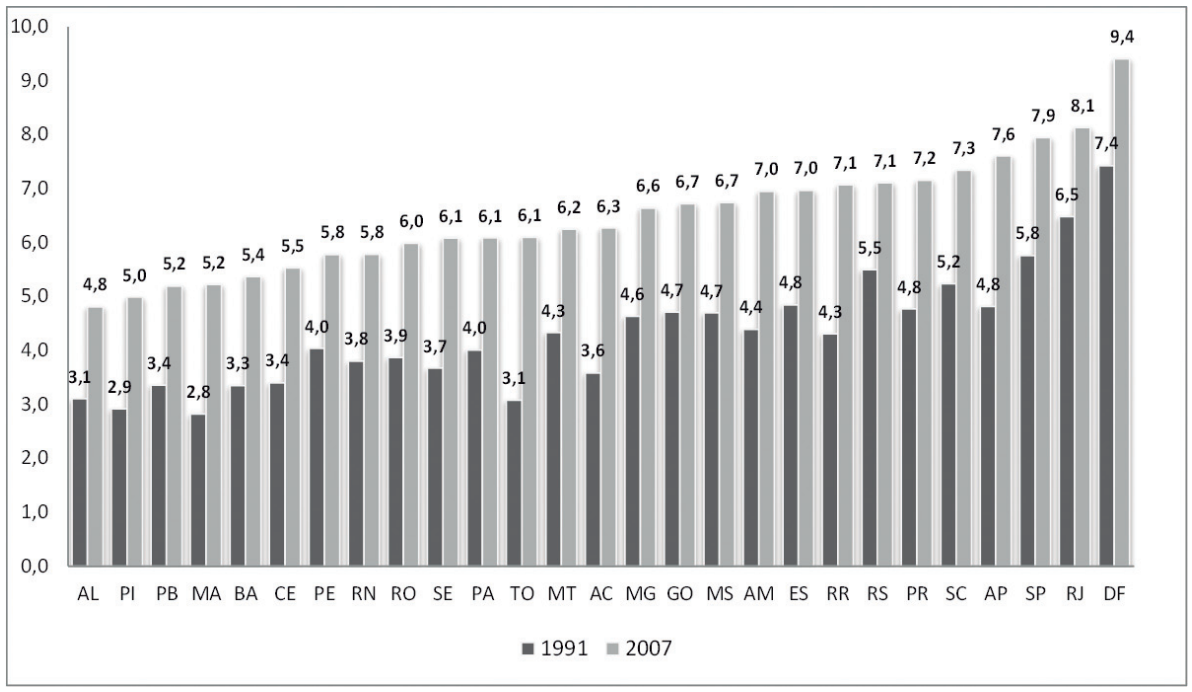

Fonte: Elaboração própria a partir de dados do Instituto de Pesquisa Econômica Aplicada (2012).

Os dados apresentados mostram que as desigualdades nos indicadores socioeconômicos ainda são consideráveis entre os estados brasileiros, como evidenciado em Barros (2011). O desafio é investigar como tais variáveis influenciam o desempenho do PIB per capita nos estados.

\section{Aplicação do Modelo Econométrico}

A investigação dos fatores de influência das desigualdades no desempenho do PIB per capita foi realizada a partir de um modelo que tomou como base as variáveis apontadas por estudos que trataram do problema na literatura. Foi utilizada uma metodologia econométrica para avaliar o nível de significância das variáveis na influência do comportamento dos PIBs per capita estaduais no Brasil. A primeira parte da seção apresenta a estratégia metodológica, com a base de dados utilizada. A segunda parte mostra os principais resultados obtidos.

\subsection{Estratégia Econométrica e Base de Dados}

O modelo utilizado buscou incorporar alguns dos principais fatores determinantes da variação do PIB per capita presentes na literatura teórica e empírica. Foram considerados os seguintes fatores: a) população, que representa o limite mínimo de crescimento do produto para manter o PIB per capita (investimento de break even); b) capital humano, como indicador do acúmulo de habilidade e 
melhoria da produtividade do trabalho; c) esperança de vida, que é uma variável de caráter social e tem influência em potencializar o capital humano disponível; d) urbanização, que representa economia de aglomeração de pessoas e habilidades em um espaço com infraestrutura disponível; e) peso do Estado, na forma de tributos, representando um maior ônus para as atividades produtivas; e f) peso dos setores de atividade no crescimento do PIB per capita.

O Quadro 1 resume a relação esperada entre o produto per capita dos estados brasileiros e as variáveis explicativas selecionadas. A análise em questão compreende os anos de 1991 a 2009, ${ }^{1}$ sob a hipótese de que as variáveis escolhidas são fatores de influência significativa do PIB per capita nesse período.

Quadro 1 - Descrição das variáveis utilizadas

\begin{tabular}{|c|c|c|c|}
\hline Variável & Descrição e fonte & $\begin{array}{l}\text { Sinal } \\
\text { esperado }\end{array}$ & Referências \\
\hline PIBpc & $\begin{array}{l}\text { PIB estadual a preços constantes. } \\
\text { Unidade } R \$(2000) \text {. Fonte: IBGE, } \\
\text { 1991-2009. }\end{array}$ & & $\begin{array}{l}\text { Ferreira e Diniz } \\
\text { (1995); Azzoni } \\
\text { et al. (2000); } \\
\text { Resende e Figue- } \\
\text { iredo (2005); } \\
\text { Amorim, Scalco } \\
\text { e Braga (2008). }\end{array}$ \\
\hline POP & $\begin{array}{l}\text { Taxa anual de crescimento da } \\
\text { população residente total. Dados } \\
\text { dos censos (1991, 2000) Contagem } \\
\text { populacional (1996), estimativas da } \\
\text { Pnad (para os demais anos). Fonte: } \\
\text { IBGE, 1991-2009. }\end{array}$ & - & $\begin{array}{l}\text { Solow (1956); } \\
\text { Barro (1996); } \\
\text { Azzoni et al. } \\
\text { (2000); Resende } \\
\text { e Figueiredo } \\
\text { (2005). }\end{array}$ \\
\hline EST & $\begin{array}{l}\text { Razão entre o somatório do número } \\
\text { de anos de estudo completados } \\
\text { pelas pessoas que possuem } 25 \text { ou } \\
\text { mais anos de idade e o número de } \\
\text { pessoas nessa faixa etária. Fonte: } \\
\text { Ipea, 1991-2009. }\end{array}$ & + & $\begin{array}{l}\text { Lucas Jr. (1988); } \\
\text { Lau et al. (1993); } \\
\text { Leedo (1996); } \\
\text { Figueiredo, } \\
\text { Noronha e An- } \\
\text { drade (2003). }\end{array}$ \\
\hline
\end{tabular}

continua...

1 Entre 1991 e 2009 houve mudanças metodológicas no cálculo do PIB por parte do IBGE. Este órgão utiliza diferentes referências como 1985 e 2002. Para saber mais, ver Nota Metodológica $n^{\circ} 26$ (IBGE, 2002). Vale salientar que, para o presente trabalho, utilizou-se uma série já compatibilizada a preços constantes de 2000 , divulgada pelo Ipeadata. 


\begin{tabular}{|c|c|c|c|}
\hline Variável & Descrição e fonte & $\begin{array}{l}\text { Sinal } \\
\text { esperado }\end{array}$ & Referências \\
\hline ESP & $\begin{array}{l}\text { Número médio de anos de vida } \\
\text { esperados para um recém-nascido, } \\
\text { mantido o padrão de mortalidade } \\
\text { existente na população residente, } \\
\text { em determinado espaço geográfico, } \\
\text { no ano considerado. Fonte: Datasus, } \\
\text { 1991-2009. }\end{array}$ & + & $\begin{array}{l}\text { Barro (1996); } \\
\text { Azzoni et al. } \\
\text { (2000); } \\
\text { Figueiredo, } \\
\text { Noronha e An- } \\
\text { drade (2003). }\end{array}$ \\
\hline URB & $\begin{array}{l}\text { Percentual da população residente } \\
\text { em áreas urbanas, em determinado } \\
\text { espaço geográfico, no ano consid- } \\
\text { erado. Fonte: IBGE, 1991-2009. }\end{array}$ & + & $\begin{array}{l}\text { Azzoni et al. } \\
\text { (2000); Oliveira } \\
\text { (2004); Resende } \\
\text { e Figueiredo } \\
\text { (2005). }\end{array}$ \\
\hline TRIB & $\begin{array}{l}\text { Relação entre arrecadação tribu- } \\
\text { tária estadual e PIB estadual. Fontes: } \\
\text { STN e IBGE, 1991-2009. }\end{array}$ & - & $\begin{array}{l}\text { Leedo (1996); } \\
\text { Arraes e Teles } \\
(2001) \text {. }\end{array}$ \\
\hline AGRO & $\begin{array}{l}\text { Taxa de variação do valor adicio- } \\
\text { nado do setor agropecuário. Fonte: } \\
\text { IBGE, 1991-2009. }\end{array}$ & + & $\begin{array}{l}\text { Ferreira e Diniz } \\
\text { (1995); Azzoni } \\
\text { (1997); Amorim, } \\
\text { Scalco e Braga } \\
\text { (2008). }\end{array}$ \\
\hline IND & $\begin{array}{l}\text { Taxa de variação do valor adicio- } \\
\text { nado do setor. Fonte: IBGE , 1991- } \\
2009 .\end{array}$ & + & $\begin{array}{l}\text { Ferreira e Diniz } \\
\text { (1995); Azzoni } \\
\text { (1997); Amorim, } \\
\text { Scalco e Braga } \\
\text { (2008). }\end{array}$ \\
\hline SERV & $\begin{array}{l}\text { Taxa de variação do valor adicio- } \\
\text { nado do setor de serviços. Fonte: } \\
\text { IBGE, 1991-2009. }\end{array}$ & + & $\begin{array}{l}\text { Ferreira e Diniz } \\
\text { (1995); Azzoni } \\
\text { (1997); Amorim, } \\
\text { Scalco e Braga } \\
\text { (2008). }\end{array}$ \\
\hline
\end{tabular}

Fonte: Elaboração própria.

A estimação proposta parte da aplicação econométrica de um modelo semilogarítmico, em que o logaritmo natural será aplicado apenas sobre a variável dependente, para refletir a variação do PIB per capita. Em uma regressão semi-log dessa natureza, cada coeficiente obtido oferece uma estimativa da variação percentual da variável dependente dada uma variação marginal na respectiva variável explicativa (coeteris paribus). ${ }^{2}$

2 O modelo semi-log tem a formulação geral dada por ln $y=x \beta+e$, em que $y$ é a variável 
O modelo semilogarítmico em questão é dado por:

$$
\begin{aligned}
& \ln P I B p c_{i t}=\beta_{0}+\beta_{1} A G R O_{i t}+\beta_{2} I N D_{i t}+\beta_{3} S E R V_{i t}+\beta_{4} P O P_{i t}+\beta_{5} E S P_{i t}+\beta_{6} E S T_{i t}+ \\
& \beta_{7} U R B_{i t}+\beta_{8} T R I B_{i t}+\mu_{i}+\varepsilon_{i t}
\end{aligned}
$$

em que $\mathrm{i}=1,2, \ldots 27$ refere-se a cada uma das $27 \mathrm{UF}, \mathrm{t}=1,2, \ldots, 19$ contabiliza as 19 observações anuais para as variáveis de cada UF (período 1991-2009), AGRO, IND e SERV representam, respectivamente, a taxa de crescimento do produto dos setores agropecuário, industrial e de serviços (medidos em termos de valor adicionado), POP é a taxa de crescimento populacional, ESP é a esperança de vida da população, EST é a variável proxy para capital humano, escolhida como sendo a média dos anos de estudos para a população com 25 anos ou mais de idade, URB é a taxa de urbanização e TRIB é a variável que mede a participação dos tributos sobre o PIB de cada estado. A variável dependente investigada, o logaritmo natural do PIB per capita dos estados, foi denominada ln PIBpc. Para uma melhor interpretação dos resultados, as escalas das variáveis foram ajustadas de modo que os coeficientes do modelo já representam as semielasticidades do PIB per capita em relação aos respectivos regressores. Nesse sentido, caso deseje-se encontrar a variação percentual discreta estimada no PIB per capita, dado uma variação unitária em alguma das variáveis, é necessário calcular $\left[\exp \left(\hat{\beta}_{k} / 100\right)-1\right] \times 100$, em que $\hat{\beta}_{k}$ é a estimativa para o coeficiente $\mathrm{k}, \mathrm{k}=1,2, \ldots, 8$. Quanto menor o valor do coeficiente estimado, maior é a aproximação da variação marginal em relação à variação discreta.

É importante salientar que um problema que frequentemente surge ao se trabalhar com dados combinados em cross-section e séries temporais é a presença de distúrbios não esféricos, principalmente heterocedasticidade entre os grupos, correlação serial de primeira ordem e correlação espacial. Para lidar com essa situação, há dois métodos bastante utilizados na literatura: o método de Parks (1967), que utiliza FGLS, e o método proposto por Beck e Katz (1995), baseado nos mínimos quadrados ordinários (OLS), mas com correção dos erros para a presença de heterocedasticidade entre os grupos, autocorrelação e correlação contemporânea. O estimador de Beck e Katz (1995) ficou conhecido como estimador PCSE. Desse modo, a estratégia econométrica envolveu a estimação de quatro modelos:

a) fixed effect model (FEM);

b) random effect model (REM);

aleatória investigada, $x$ é um vetor $1 x K$ de variáveis explicativas, $\beta$ é um vetor $K x 1$ de coeficientes e $e$ é o termo de erro. A variação percentual estimada de y dada uma mudança marginal em uma determinada variável explicativa $x_{i}$, ou semielasticidade de $y$ em relação a $x_{i}$, é dada por $100 \cdot \partial \ln [E(y \mid \mathrm{x})] / \partial x_{j}$, se $[E(y \mid \mathbf{x})]>0$ (WOOLDRIDGE, 2002, p. 18). 
c) feasible generalized least squares (FGLS);

d) panel-corrected standard errors (PCSE).

Nos modelos propostos, supõem-se a existência de efeitos individuais não observáveis dos estados, incorporados por meio do termo $\mu_{i}$. O modelo é unidirecional, portanto não se supõe a existência de efeitos de tempo. Se os efeitos específicos dos estados forem tratados como uma variável aleatória, tem-se que $\mu_{i} \sim \operatorname{IID}\left(0, \sigma_{\mu}^{2}\right), \varepsilon_{i t} \sim \operatorname{IID}\left(0, \sigma_{\varepsilon}^{2}\right), \mu_{\mathrm{i}}$ é independente do termo de erro idiossincráti$\operatorname{co} \varepsilon_{\text {it }}$ e os regressores são independentes de $\mu_{\mathrm{i}}$ e $\varepsilon_{\mathrm{it.}}$ Essa é a abordagem do modelo de efeitos aleatórios (REM). Por outro lado, caso se assuma que $\mu_{\mathrm{i}}$ são parâmetros fixos a serem estimados, com $\varepsilon_{i t} \sim \operatorname{IID}\left(0, \sigma_{\varepsilon}^{2}\right)$ e os regressores independentes de $\varepsilon_{\text {it }}$ tem-se a abordagem FEM. Nesse caso, não se assume independência entre as variáveis explicativas e a heterogeneidade não observável dos indivíduos. O modelo com efeitos fixos torna-se mais apropriado que o modelo com efeitos aleatórios se houver correlação entre os efeitos individuais e os regressores (BALTAGI, 2005).

Há, por sua vez, três categorias importantes de erros não esféricos que podem estar contidos em dados longitudinais: a) heterocedasticidade entre os grupos; b) correlação serial de primeira ordem; e c) correlação contemporânea, ou correlação espacial (dependência em cross-section). Nesse cenário, os distúrbios do modelo assumem a seguinte especificação (KMENTA, 1986):

$$
E\left(\varepsilon_{i t}^{2}\right)=\sigma_{i i}
$$

(heterocedasticia entre os grupos)

$$
E\left(\varepsilon_{i t} \varepsilon_{j t}\right)=\sigma_{i j}
$$

(correlação espacial)

$$
\varepsilon_{i t}=\rho_{i} \varepsilon_{i, t-1}+u_{i t}
$$

(autocorrelação de primeira ordem)

Com $\left.u_{i t} \sim N\left(0, \phi_{i i}\right) ; E\left(\varepsilon_{i, t-1} u_{j l}\right)=0 E\left(u_{i t} u_{j l}\right)=\phi_{i j}(t=s) ; E\left(u_{i t} u_{j s}\right)=0(t \neq s) ; \sigma_{i i}=\phi_{i i} / 1-\rho_{i}^{2}\right) ;$ $\sigma_{i j}=\phi_{i j} /\left(1-\rho_{i} \rho_{j}\right) ; i, j=1,2, \ldots, N ; t=1,2, \ldots, T$. Ademais, para o termo de erro inicial assume-se $\varepsilon_{i 1} \sim N\left(0, \phi_{i j} /\left(1-\rho_{i} \rho_{j}\right)\right)$.

Na presença de distúrbios não esféricos, o método OLS produz estimativas ineficientes para os coeficientes, e os correspondentes erros padrão tornam-se viesados. Parks (1967) propõe um método de estimação baseado nos mínimos quadrados generalizados (GLS) que corrige essas estruturas de erro, produzindo coeficientes assintoticamente eficientes e erros padrão não tendenciosos. Esse método assume que a estrutura da covariância dos erros está corretamente especificada e que os elementos da matriz de covariância dos erros são conhecidos. Quando o processo gerador dos erros não é conhecido, os elementos da matriz 
de covariância dos erros devem ser estimados, o que pode ser feito por meio do método FGLS.

Beck e Katz (1995) desenvolveram um importante estudo em que questionam a eficiência do método de Parks em situações comumente encontradas por pesquisadores. Segundo os autores, o método FGLS subestima sensivelmente a variância dos parâmetros, o que infla a confiabilidade das estimativas. Para contornar esse problema, Beck e Katz (1995) propõem um estimador alternativo baseado no OLS que corrige para as três categorias de erros não esféricos. Esse método ficou conhecido como estimador com erros padrão corrigidos, ou PCSE. As simulações Monte Carlo realizadas por esses autores mostraram que o método PCSE produz estimativas mais precisas dos erros, com pouca ou nenhuma perda de eficiência se comparado ao FGLS de Parks (1967), exceto em situações extremas de heterocedasticidade ou correlação contemporânea, situação que, segundo os autores, não ocorre na prática.

Contudo, trabalhos recentes têm demonstrado que o método PCSE não é tão preciso quanto atesta Beck e Katz (1995). Chen, Lin e Reed (2010), Reed e Weeb (2010) e Reed e Ye (2011) mostraram, por meio de simulações Monte Carlo, que há diversas "situações práticas de pesquisa" em que o estimador PCSE é substancialmente menos eficiente do que o método FGLS. Isso ocorre principalmente quando o número de observações temporais $(T)$ é superior às unidades cross-section $(N)$. Quando T é próximo de $N$, o método PCSE geralmente apresenta um melhor desempenho na estimativa dos erros padrão em comparação ao FGLS. Entretanto, conforme o período de tempo aumenta a eficiência relativa das estimativas por PCSE, diminui ainda mais. Na análise do presente trabalho, portanto, em que o número de unidades $(N)$ é superior às observações temporais $(T)$, o método PCSE será tomado como referência principal por causa de seu desempenho frente aos demais.

Toda a análise econométrica foi realizada utilizando o software Stata, versão 11. O Quadro 2 apresenta os testes empregados para identificar possíveis diferentes estruturas na matriz de variância-covariância dos erros no painel de dados. 
Quadro 2 - Testes utilizados para identificação de erros não esféricos

\begin{tabular}{|l|l|}
\hline Teste & Hipótese nula \\
\hline Greene para heterocedasticidade & Homocedasticia entre os grupos \\
Friedman & Independência cross-section \\
Frees & Independência cross-section \\
Pesaran & Independência cross-section \\
Wooldridge para autocorrelação & Não há correlação serial de primeira \\
& ordem \\
\hline
\end{tabular}

Fonte: Elaboração própria.

Para testar a hipótese de heterocedasticidade entre os grupos utilizou-se o teste Wald proposto por Greene (2000, p. 598), implementado no Stata por Baum (2001). A hipótese de correlação espacial foi investigada através de três diferentes testes: teste de Friedman (1937), teste de Frees (1995) e teste de Pesaran (2004), todos os três implementados no Stata por Hoyos e Sarafidis (2006). O teste do multiplicador de lagrange de Breusch e Pagan (1980) é geralmente o mais empregado para testar dependência entre as unidades cross-section em um painel de dados, porém o teste supõe $N$ fixo e $\mathrm{T} \rightarrow \infty$. O teste de Friedman, o teste de Frees e o teste de Pesaran, por outro lado, são válidos quando $T<N$, situação encontrada no estudo em questão. A presença de correlação serial foi testada com uso do teste de Wooldridge (2002), introduzido no Stata por Drukker (2003).

Como será visto na próxima seção, os testes para a presença de distúrbios não esféricos apontaram a existência de heterocedasticidade, autocorrelação e correlação espacial no modelo econométrico proposto. Nessa situação, os modelos de painel por efeitos fixos e por efeitos aleatórios não apresentam estimativas adequadas, sendo apropriado estimar pelos modelos FGLS e PCSE. A discussão existente na literatura acerca da melhoria das estimativas por PCSE em relação às estimativas obtidas por FGLS torna válida a comparação dos resultados desses dois importantes métodos, com ênfase no primeiro.

\subsection{Análise dos Resultados}

A Figura 1 mostra os gráficos de dispersão entre a variável dependente investigada e as variáveis explicativas selecionadas. É perceptível a relação positiva entre o logaritmo do PIB per capita e as variáveis expectativa de vida, anos de estudo e taxa de urbanização. Para as demais variáveis, porém, as nuvens de pontos não apresentam uma relação claramente identificável. A tabela de correlação entre as variáveis selecionadas e demais estatísticas descritivas encontram-se no Apêndice A. 
Figura 1 - Gráficos de dispersão entre o logaritmo natural do PIB per capita (eixo das ordenadas) e as demais variáveis selecionadas
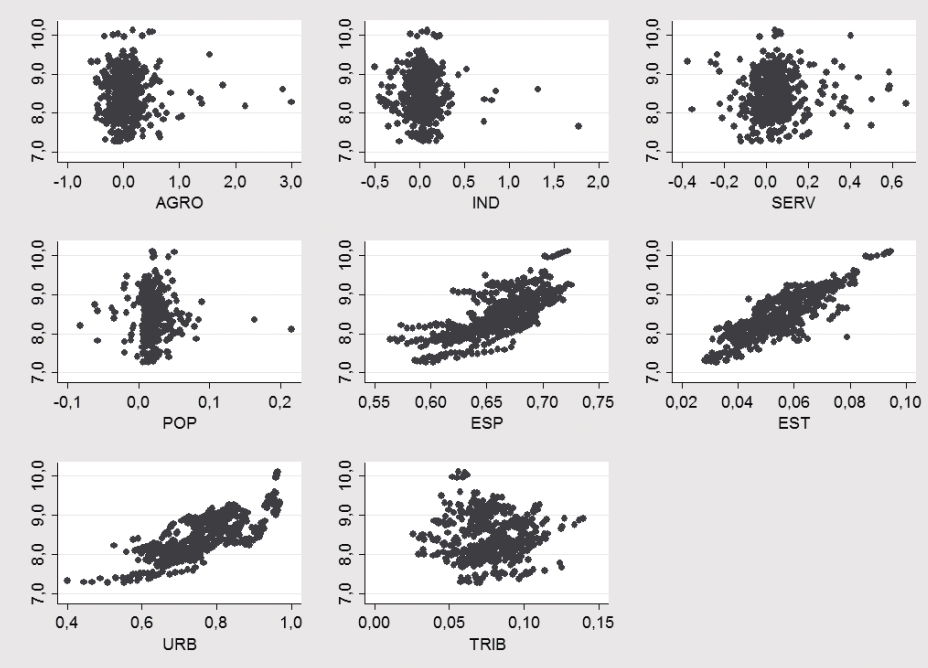

Fonte: Elaboração própria.

O modelo econométrico foi estimado primeiramente por meio do estimador FEM e do estimador GLS de efeitos aleatórios (REM), e foi utilizado o teste de Hausman (1978) para concluir qual abordagem, FEM ou REM, é mais adequada. Com base no teste de Hausman, cujo resultado consta na Tabela 2, rejeitou-se a hipótese nula em favor do modelo de efeitos aleatórios, o que sugere a utilização do modelo de efeitos fixos. Vale ressaltar que a hipótese nula de que não há efeitos individuais, isto é, $H_{0}: \mu_{i}=0 \forall i$, foi rejeitada $\left(F_{(26,478)}=69,10 ; p=0,000\right)$.

A Tabela 1 apresenta os resultados dos testes aplicados para identificar no FEM as três categorias de erros não esféricos discutidas na seção anterior. De acordo com o teste de Greene, a hipótese nula de homocedasticidade entre os estados, $H_{0}: \sigma_{i}^{2}=\sigma^{2} \forall i$, foi rejeitada ao nível de significância de $1 \%$, o que é bastante plausível caso se considerem as diferenças intra e inter-regionais na renda per capita dos estados brasileiros. A hipótese de independência entre as unidades cross-section também foi rejeitada a $1 \%$ com base nos três testes de correlação contemporânea utilizados, o que pode estar relacionado à existência de correlação espacial entre as rendas per capita dos estados. Por fim, o resultado obtido para o teste de Wooldridge identifica um processo autorregressivo de primeira ordem nos resíduos. 
Tabela 1 - Resultado dos testes utilizados para identificação de erros não esféricos

\begin{tabular}{|c|c|}
\hline Teste & Valor \\
\hline Greene para heterocedasticidade & $\begin{array}{l}W=10036,60 \\
p=0,0000\end{array}$ \\
\hline Friedman & $\begin{array}{l}F R=119,120 \\
p=0,0000\end{array}$ \\
\hline Frees & $\begin{array}{l}\mathrm{FRE}=5,337 \\
\text { Valor crítico a } 1 \%=0,2928\end{array}$ \\
\hline Pesaran & $\begin{array}{l}C D=23,195 \\
p=0,0000\end{array}$ \\
\hline Wooldridge para autocorrelação & $\begin{array}{l}F_{(1,26)}=142,948 \\
p=0,0000\end{array}$ \\
\hline
\end{tabular}

Fonte: Elaboração própria.

A evidência de heterocedasticidade entre os grupos, correlação contemporânea e autocorrelação sugere a aplicação dos métodos FGLS e PCSE para estimar os coeficientes e os erros padrão do modelo. Para fins de comparação com as estimativas do método FEM, as variáveis foram centradas com relação às respectivas médias, eliminando, assim, os efeitos não observáveis e o termo constante.

Na Tabela 2 vê-se que os coeficientes das variáveis IND e EST produzidos pela estimativa por FEM não foram estatisticamente significativos. As demais variáveis foram significativas, com os sinais esperados para os coeficientes. O fato de a taxa de crescimento do setor industrial e a variável anos de estudo não apresentarem uma relação significativa com o PIB per capita dos estados vai de encontro ao constatado pela literatura apresentada na seção 2. Esses resultados podem estar associados com a violação das pressuposições clássicas do modelo de efeitos fixos e a consequente presença de distúrbios não esféricos nos dados. 
Tabela 2 - Estimativas para os determinantes do PIB per capita dos estados brasileiros

\begin{tabular}{lllll}
\hline Variável & REM & FEM & FGLS & PCSE \\
\hline AGRO & $0,0580 * * *$ & $0,0553 * *$ & $0,0453 * * *$ & $0,0489 * * *$ \\
\multirow{2}{*}{ IND } & $(0,0166)$ & $(0,0160)$ & $(0,0026)$ & $(0,0114)$ \\
& 0,0277 & 0,0324 & $0,0628 * * *$ & $0,0637 * * *$ \\
SERV & $(0,0368)$ & $(0,0363)$ & $(0,0033)$ & $(0,0212)$ \\
& $0,1160 * * *$ & $0,1439 * * *$ & $0,1810 * * *$ & $0,1768 * * *$ \\
POP & $(0,0316)$ & $(0,0344)$ & $(0,0089)$ & $(0,0475)$ \\
& $-0,5102 *$ & $-0,5100 * *$ & $-0,4705 * * *$ & $-0,5202 * *$ \\
ESP & $(0,2811)$ & $(0,2095)$ & $(0,0508)$ & $(0,2435)$ \\
& $6,5323 * * *$ & $7,6601 * * *$ & $5,7849 * * *$ & $5,4813 * * *$ \\
EST & $(1,7043)$ & $(2,1529)$ & $(0,3089)$ & $(0,9674)$ \\
& 2,6754 & 0,5947 & $3,1884 * * *$ & $3,2768 *$ \\
URB & $(4,0254)$ & $(3,8833)$ & $(0,2686)$ & $(1,6829)$ \\
& $2,0020 * * *$ & $1,4435 *$ & $1,2024 * * *$ & $1,2749 * * *$ \\
TRIB & $(0,4443)$ & $(0,7101)$ & $(0,1287)$ & $(0,3014)$ \\
& $-5,6772 * * *$ & $-5,5464 * * *$ & $-2,5508 * * *$ & $-2,6011 * * *$ \\
& $(1,4764)$ & $(1,5953)$ & $(0,0929)$ & $(0,6239)$ \\
\hline \multirow{2}{*}{$R^{2}$} & Within $=0,69$ & Within $=0,69$ & & \\
& Between $=$ & Between $=0,80$ & - & 0,60 \\
& 0,82 & & & \\
Hausman & Overall $=0,80$ & Overall $=0,77$ & & \\
& $x^{2}=92,70$ & & & \\
\hline & $p=0,0000$ & & & \\
\hline
\end{tabular}

Fonte: Elaboração própria.

Notas: * * Significante a 1\%; * Significante a 5\%; * Significante a 10\%. Erros padrão entre parênteses.

Os resultados apresentados na Tabela 2 mostram uma melhora nas estimativas ao se aplicar os métodos FGLS e PCSE. Todos os coeficientes gerados são significativos e os sinais atendem ao esperado. Em particular, todos os coeficientes estimados via FGLS são significativos a 1\%. Há também uma sensível mudança na magnitude da maioria dos coeficientes ao se comparar as estimativas FEM com as estimativas FGLS e PCSE.

No que toca aos coeficientes estimados para as taxas de crescimento dos grandes setores econômicos, tem-se que o setor de serviços apresenta o coeficiente de maior magnitude, o que é esperado devido ao aumento expressivo da 
participação desse setor no PIB per capita dos estados ao longo do período estudado. Segundo os resultados do método PCSE, estima-se que um aumento de um ponto percentual na taxa de crescimento do setor de serviços gera um aumento de $0,1768 \%$ no PIB per capita dos estados. Para o setor industrial, estima-se que o incremento de um ponto percentual na taxa de crescimento do seu valor adicionado produz um ganho no PIB per capita estadual de, 0,0637\%. O crescimento do setor agropecuário, por sua vez, apresenta um efeito marginal estimado menor sobre o PIB per capita, 0,0489\% pelo método PCSE. Essas estimativas acabam por refletir a recomposição do peso dos setores no PIB per capita da maioria dos estados, conforme apresentado na seção 3.

As variáveis anos de estudo (EST) e esperança de vida ao nascer (ESP) apresentam um efeito positivo importante sobre o PIB per capita estadual de acordo com os resultados obtidos. Em termos discretos o aumento de um ano na expectativa de vida da população eleva o PIB per capita em $[\exp (0,054813)-1] \times 100 \cong 5,63 \%$ pela estimativa PCSE.

Para cada aumento discreto de um ano na média de anos de estudo, gera-se um acréscimo estimado no PIB per capita estadual de aproximadamente 3,33\% via PCSE. Tem-se, portanto, que uma maior capacitação do capital humano em termos da quantidade de anos de estudo, e um aumento da esperança de vida, que potencializa esse capital humano, influenciam positivamente e de forma significativa o crescimento do PIB.

A taxa de urbanização também apresenta uma influência positiva significativa sobre o PIB per capita. O aumento de um ponto percentual na taxa de urbanização dos estados eleva, em termos marginais, a respectiva renda per capita em 1,2749\% segundo a estimativa PCSE, o que é uma indicação da importância das economias de aglomeração.

Outro importante resultado é o apontado pelas estimativas do coeficiente da variável TRIB. Os resultados mostram que o aumento da participação tributária sobre o PIB dos estados produz um efeito negativo de considerável magnitude sobre o produto per capita. Estima-se, pelo método PCSE, que uma variação de um ponto percentual no peso dos tributos sobre o PIB estadual reduz o produto per capita em $2,6011 \%$, coeteris paribus. Uma das possíveis interpretações desses resultados é que o maior peso do Estado vem a gerar um maior ônus para as atividades produtivas, o que, sem uma correspondente contrapartida adequada, acaba por prejudicar o crescimento econômico.

Por fim, é perceptível a diferença entre os métodos FGLS e PCSE quanto às estimativas dos erros padrão dos coeficientes. Entretanto, deve-se ter cautela ao se decidir qual dos dois modelos é o mais apropriado. Beck e Katz (1995) demonstraram que em muitas situações o método de Parks subestima a variabilidade dos parâmetros, o que infla a confiabilidade das estimativas. Em princípio, para utilizar 
resultados mais conservadores, tomou-se como base as estimativas obtidas por meio do PCSE. Mas é importante perceber que, em termos qualitativos, os resultados dos dois métodos são muito próximos, tendo em vista que os coeficientes estimados por ambos apresentam o sinal esperado e com magnitudes semelhantes.

\section{Considerações Finais}

O presente estudo investigou os fatores que têm influência no desempenho do PIB per capita dos estados, buscando trazer evidências empíricas sobre o que apresenta a literatura. O trabalho envolveu a aplicação de um modelo baseado em algumas das principais variáveis apontadas pela literatura, além de avançar em relação à correção de erros nas estimativas, verificados nos modelos tradicionais de painel de dados.

O modelo utilizado compreende oito variáveis explicativas selecionadas, baseadas na literatura teórica (taxa de crescimento populacional e média de anos de estudo) e na literatura empírica de crescimento (esperança de vida da população, taxa de urbanização, participação tributária e taxas de crescimento dos setores agropecuário, industrial e de serviços), além do PIB per capita. A amostra compreendeu as 27 UF entre os anos de 1991 a 2009

Nas estimativas, aplicou-se um modelo econométrico com efeitos individuais para o painel de dados, utilizando-se os modelos de efeitos fixos e efeitos aleatórios. Entretanto, foi identificada a presença de heterocedasticidade entre os estados, correlação serial de primeira ordem nos resíduos e correlação contemporânea. A presença desses distúrbios não esféricos, configurando a presença de uma estrutura complexa dos erros, aponta para a necessidade de utilização dos métodos FGLS e PCSE, capazes de gerar estimativas eficientes para os coeficientes com correspondentes erros padrão não tendenciosos.

A aplicação desses métodos mostram resultados mais consistentes que aqueles obtidos através dos modelos em painel por efeitos fixos e por efeitos aleatórios, que apresentaram variáveis não significativas nas estimativas. Os resultados dos modelos FGLS e, sobretudo, PCSE, que corrigem adequadamente os erros de estimação, apresentaram todos os coeficientes significativos e com sinais esperados, corroborando os resultados apontados pela literatura. Os resultados obtidos por meio do PCSE, tomados como base para a análise, estão bastante próximos dos obtidos através do FGLS, embora os estimadores deste último tendam a superestimar a confiabilidade dos estimadores. A estimação pelo PCSE, uma das principais contribuições deste trabalho, mostra que os fatores de influência utilizados no modelo são capazes de explicar o desempenho do PIB per capita dos estados. Os achados apresentados podem dar suporte ao encaminhamento de prioridades na formulação de políticas públicas que tenham por objetivo incrementar o PIB 
per capita nos estados, devendo ser consideradas as diversas heterogeneidades inerentes às UF.

Nesse sentido, uma linha de ação importante aponta que o governo deve continuar investindo na qualidade de vida da população, principalmente no que remete à educação e à saúde, que impactam positivamente no produto per capita dos estados brasileiros. Ressalta-se uma atenção especial através de programas regionais direcionados para os estados do Norte e Nordeste que, historicamente, segundo Furtado (1959), Diniz (2006) e Barros (2011), apresentam baixos índices educacionais e de saúde. Adicionalmente, os resultados apontam, sob a perspectiva da economia de aglomeração, que a preocupação com a infraestrutura urbana deve ser uma outra linha de ação importante nos estados.

Outro importante resultado indica que a questão tributária deve ser objeto de ações mais efetivas dos governos, uma vez que a arrecadação tributária, ao onerar demais a estrutura produtiva, tem exercido influência negativa sobre o crescimento econômico dos estados. Por fim, em relação a políticas setoriais, embora o setor serviços tenha apresentado efeitos maiores sobre o desempenho do PIB per capita, não se pode perder de vista o incentivo à produção nas atividades industriais, uma vez que estas têm a capacidade de alavancar a economia mais rapidamente, além do que suas relações intersetoriais impactam positivamente outros segmentos da economia. De forma complementar, as atividades primárias devem receber investimentos e/ou subsídios que aumentem sua produtividade, uma vez que esse segmento representa o principal fornecedor de insumos dos setores industriais, refletindo em fortes impactos a jusante das cadeias produtivas dos estados brasileiros.

Em relação a estudos futuros, pode-se estender a análise feita neste trabalho de diversas maneiras, principalmente no que remete à metodologia aplicada. Métodos para a estimação robusta na presença de outliers, teste para a presença de coeficientes aleatórios e aplicação dos métodos de painel dinâmico com o uso de estimadores Arellano-Bond são abordagens que podem oferecer outras conclusões elucidativas.

\section{Referências}

AMORIM, A. L.; SCALCO, P. R.; BRAGA, M. J. Crescimento econômico e convergência de renda nos estados brasileiros: uma análise a partir dos grandes setores da economia. Revista Econômica do Nordeste, v. 39, n. 3, p. 359-370, jul./set. 2008.

ARRAES, R. A.; TELES, V. K. Política fiscal e crescimento econômico: aspectos teóricos e evidências empíricas para as regiões brasileiras. Revista Econômica do Nordeste, v. 32, n. especial, p. 676-690, nov. 2001. 
AZZONI, C. R. Concentração regional e dispersão das rendas per capita estaduais: análise a partir de séries históricas estaduais de PIB, 1939-1995. Estudos Econômicos, v. 27, n. 3, p. 341-93, set.-dez. 1997.

AZZONI, C.; MENEZES, T.; MENEZES, N.; NETO, R. Geografia e convergência da renda entre os estados brasileiros. In: HENRIQUES, R. (Org.). Desigualdade e pobreza no Brasil. Rio de Janeiro: Ipea, 2000. p. 299-343.

BALTAGI, B. Econometric analysis of panel data. 3. ed. John Wiley E Sons, 2005.

BARRO, R. J. Determinants of economic growth: a cross-country empirical study. Cambridge, MA: National Bureau Economic Research, 1996. (NBER Working Paper Series, 5698).

. Growth in a cross section of countries. The Quarterly Journal of Economics, v. 106, n. 2, p. 407-403, May 1991.

BARRO, R. J.; SALA-I-MARTIN, X. Economic growth. London: McGraw-Hill, Inc, 2003.

BARROS, A. R. Desigualdades regionais no Brasil: natureza, causas, origens e solução. Rio de Janeiro: Elsevier, 2011.

BAUM, C. Residual diagnostics for cross-section time series regression models. The Stata Journal, v. 1, n. 1, p. 101-104, 2001.

BECK, N.; KATZ, J. What to do (and not to do) with time series cross-section data. American Political Science Review, v. 89, n. 3, p. 634-647, Sept. 1995.

BECKER, G. S. Human capital a theoretical and empirical analysis, with special reference to education. New York: Columbia University Press, 1964.

BRASIL. Ministério da Fazenda. Secretaria do Tesouro Nacional. Séries temporais: execução orçamentária da União, Estados e Distrito Federal. 2009. Disponível em: < http://www3. tesouro.fazenda.gov.br/series_temporais/principal.aspx?tema=4\# ancora_consulta $>$. Acesso em: 22 dez. 2012.

BREUSCH, T.; PAGAN, A. The Lagrange multiplier test and its application to model specification in econometrics. Review of Economic Studies, v. 47, p. 239-253, Jan. 1980.

CHEN, X.; LIN, S.; REED, W. A Monte Carlo evaluation of the efficiency of the PCSE estimator. Applied Economics Letters, v. 17, n. 1, p.7-10, 2010.

DINIZ, C. C. A busca de um projeto de nação: o papel do território e das políticas regional e urbana. Revista Economia, v. 7, n. 4, p. 1-18, 2006.

DRUKKER, D. M. Testing for serial correlation in linear panel-data models. The Stata Journal, V. 3, n. 2, p. 168-177, 2003.

FERRARIO, M. N. et al. Uma análise espacial do crescimento econômico do estado do Paraná para os anos 2000 e 2004. Revista Brasileira de Estudos Regionais e Urbanos, v. 3, n. 1, p. 154-177, 2009. 
FERREIRA, A. H. B.; DINIZ, C. C. Convergência entre as rendas per capita estaduais no Brasil. Revista de Economia Política, v. 15, n. 4, p. 38-56, out./dez. 1995.

FIGUEIREDO, L.; NORONHA, K. V.; ANDRADE, M. V. Os impactos da saúde sobre o crescimento econômico na década de 90: uma análise para os estados brasileiros. Belo Horizonte: UFMG/Cedeplar, 2003. (Texto para Discussão, n. 219).

FREES, E. Assessing cross-sectional correlation in panel data. Journal of Econometrics, v. 69, n. 2, p. 393-414, Oct. 1995.

FRIEDMAN, M. The use of ranks to avoid the assumption of normality implicit in the analysis of variance. Journal of the American Statistical Association, v. 32, n. 200, p. 675-701, Dec. 1937.

FURTADO, C. A. Operação Nordeste. Rio de Janeiro: Instituto Superior de Estudos Brasileiros, 1959.

GONDIM, J. L. B.; BARRETO, F. A.; CARVAlHO, J. R. Condicionantes de clubes de convergência no Brasil. Estudos Econômicos, São Paulo, v. 37, n.1, p. 71-100, jan./ mar. 2007.

GREENE, W. Econometric analysis. 4. ed. New Jersey: Prentice-Hall, 2000.

HAUSMAN, J. Specification tests in Econometrics. Econometrica, v. 46, n. 6, p. 1251-1271, Nov. 1978.

HOYOS, R.; SARAFIDIS, V. Testing for cross-sectional dependence in panel-data models. The Stata Journal, v. 6, n. 4, p. 482-496, 2006.

INSTITUTO BRASILEIRO DE GEOGRAFIA E ESTATÍSTICA. Censos Demográficos. 1991. Disponível em: <http://ibge.gov.br/home/estatistica/populacao/censodem/default censo1991.shtm>. Acesso em: 19 dez. 2012.

. Contas regionais do Brasil - 2010. Disponível em: < http://ibge.gov.br/home/estatistica/ economia/contasregionais/2010/default_serie_xls_zip.shtm>. Acesso em: 19 dez. 2012.

. Diretoria de Pesquisas. Coordenação de Contas Nacionais. Contas regionais do Brasil: referência 2002. (Nota Medotológica, n. 26). Disponível em: <ftp://ftp.ibge.gov.br/Contas Nacionais/Sistema_de_Contas_Nacionais/Notas_Metodologicas/26_RetropolacaoRegional. pdf > . Acesso em: $\overline{1} 9$ dez. 2012.

. Estimativas populacionais. 2009. Disponível em: < http://ibge.gov.br/home/estatistica/

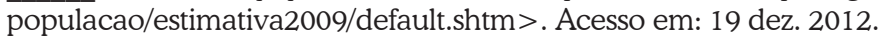

INSTITUTO DE PESQUISA ECONÔMICA APLICADA. Ipeadata. Dados Sociais. Tema educação. Anos de estudo - média - pessoas de 25 anos e mais. 2012. Disponível em: <http:// www.ipeadata.gov.br>. Acesso em: 21 dez. 2012.

KMENTA, J. Elements of econometrics. 2. ed. Ann Arbor: The University of Michigan Press, 1997. 
LAU, L. J. et al. Education and economic growth: some cross sectional evidence from Brazil. Journal of Development Economics, n. 41, p. 45-70, June 1993.

LLÉDO, V. D. Distribuição de renda, crescimento endógeno e política fiscal: uma análise cross-section para os estados brasileiros. Rio de Janeiro: Ipea, 1996. (Texto para Discussão, n. 441).

LUCAS JR.; R. E. On the mechanics of economic development. Journal of Monetary Economics, v. 22, p. 3-42, 1988.

MANKIW, N. G.; ROMER, D.; WEIL, D. N. A contribution to the empirics of economic growth. The Quarterly Journal of Economics, v. 107, n. 2, p. 407-37, 1992.

MENEZES, T.; FERREIRA JR., D. Migração e convergência de renda. São Paulo: Nereus, 2003. (Texto para discussão, 13).

MONASTERIO, L. M.; ÁVILA, R. P. Uma análise espacial do crescimento econômico do Rio Grande do Sul (1939-2001). Economia, v. 5, n. 2, p. 269-96, 2004

OLIVEIRA, C. A. Crescimento econômico das cidades nordestinas: um enfoque da nova geografia econômica. Revista Econômica do Nordeste, Fortaleza, v. 35, n. 3, jul.-set. 2004.

PARKS, R. Efficient estimation of a system of regression equations when disturbances are both serially and contemporaneously correlated. Journal of the American Statistical Association, v. 62, n. 318, p. 500-509, June 1967.

PESARAN, M. General diagnostic tests for cross section dependence in panels. Cambridge, MA: University of Cambridge, Faculty of Economics, 2004. (Working Papers in Economics, $\mathrm{n}$. 435).

REED, W.; WEEB, R. The PCSE estimator is good - just not as good as you think. Christchurch: University of Canterbury, Department of Economics and Finance, 2010. (Economics Working Paper, n. 53).

REED, W.; YE, H. Which panel data estimator should I use? Applied Economics, v. 43, n. 8, p. 985-1000, Mar. 2011.

RESENDE, G. M. Multiple dimensions of regional economic growth: the Brazilian case, 1991-2000. Papers in Regional Science, v. 90, n. 3, p. 629-663, 2011.

RESENDE, G. M.; FIGUEIREDO, L. Testes de robustez: uma aplicação para os determinantes das taxas de crescimento do produto interno bruto per capita dos estados brasileiros. Brasília, DF: Ipea, 2005. (Texto para Discussão, n. 1124).

RIBEIRO, E. C. B. A.; ALMEIDA, E. S. Convergência local de renda no Brasil. Economia Aplicada, Ribeirão Preto, v. 16, n. 3, p. 399-420, Set. 2012.

SILVEIRA NETO, R.; AZZONI, C. R. Location and regional income disparity dynamics: the Brazilian case. Papers in Regional Science, v. 25, n. 4, p. 599-613, 2006.

SOLOW, R. M. A contribution to the theory of economic growth. Quarterly Journal of Economics, v. 70, p. 65-94, 1956. 
SOUZA, M. R. P. Análise da variável escolaridade como fator determinante do crescimento econômico. Revista FAE, Curitiba, v. 2, n.3, p. 47-56, set./dez. 1999.

WOOLDRIDGE, J. M. Econometric analysis of cross section and panel data. Cambridge, MA: MIT Press, 2002.

\section{Apêndice A}

Tabela 3 - Correlações entre as variáveis selecionadas (1991-2009)

\begin{tabular}{l|lllllllll}
\hline Variável & $\ln$ PIBpc & AGRO & IND & SERV & POP & ESP & EST & URB & TRIB \\
\hline ln PIBpc & 1,0000 & & & & & & & & \\
AGRO & 0,0981 & 1,0000 & & & & & & & \\
IND & 0,0545 & 0,0504 & 1,0000 & & & & & & \\
SERV & 0,2418 & 0,1530 & $-0,0398$ & 1,0000 & & & & & \\
POP & $-0,1706$ & 0,0596 & 0,0875 & 0,0374 & 1,0000 & & & & \\
ESP & 0,7340 & 0,0205 & 0,0081 & 0,0813 & $-0,1223$ & 1,0000 & & & \\
EST & 0,8348 & 0,0395 & $-0,0268$ & 0,0457 & $-0,1982$ & 0,7520 & 1,0000 & & \\
URB & 0,8058 & $-0,0085$ & $-0,0164$ & 0,0304 & $-0,1227$ & 0,6005 & 0,7907 & 1,0000 & \\
TRIB & $-0,0890$ & $-0,0093$ & $-0,0036$ & 0,0441 & $-0,0325$ & 0,2944 & 0,0256 & 0,4673 & 1,0000 \\
\hline
\end{tabular}

Fonte: Elaboração própria.

Tabela 4 - Estatísticas descritivas (1991-2009)

\begin{tabular}{l|lllllllll}
\hline Estatística & PIBpc & AGRO & IND & SERV & POP & ESP & EST & URB & TRIB \\
\hline Média & 5509,95 & 0,0543 & 0,0366 & 0,0464 & 0,0189 & 66,0198 & 5,5574 & 0,7680 & 0,0782 \\
Mediana & 4429,19 & $-0,001$ & 0,0375 & 0,0401 & 0,0159 & 66,4000 & 5,5311 & 0,7610 & 0,0778 \\
Variância & $1,16 \mathrm{e}+07$ & 0,1124 & 0,0302 & 0,0123 & 0,0003 & 10,7147 & 1,5814 & 0,0111 & 0,0003 \\
Desvio Padrão & 3409,55 & 0,3353 & 0,1740 & 0,1109 & 0,0194 & 3,2733 & 1,2575 & 0,1057 & 0,0187 \\
Assimetria & 2,1881 & 3,8161 & 2,9941 & 1,5158 & 2,6152 & $-0,4590$ & 0,2790 & $-0,044$ & 0,0376 \\
Curtose & 10,6594 & 28,457 & 29,804 & 10,019 & 31,901 & 2,7222 & 2,8987 & 2,8092 & 3,1914 \\
Observações & 513 & 513 & 513 & 513 & 513 & 513 & 513 & 513 & 513 \\
\hline
\end{tabular}

Fonte: Elaboração própria.

Tabela 5 - Estatísticas descritivas (1991)

\begin{tabular}{l|lllllllll}
\hline Estatística & PIBpc & AGRO & IND & SERV & POP & ESP & EST & URB & TRIB \\
\hline Média & 4821,64 & $-0,024$ & 0,0189 & 0,0595 & 0,0250 & 62,7407 & 4,3299 & 0,6967 & 0,0663 \\
Mediana & 3890,26 & $-0,090$ & 0,0293 & 0,0706 & 0,0212 & 63,5000 & 4,3110 & 0,7060 & 0,0647 \\
Variância & $7,7 \mathrm{e}+06$ & 0,1228 & 0,0082 & 0,0133 & 0,0001 & 8,7978 & 1,2053 & 0,0168 & 0,0003 \\
Desvio Padrão & 2768,01 & 0,3504 & 0,0910 & 0,1154 & 0,0136 & 2,9661 & 1,0979 & 0,1298 & 0,0189 \\
Assimetria & 1,2532 & 3,2498 & 0,4676 & $-1,082$ & 1,7141 & $-0,4385$ & 0,9376 & 0,1253 & 0,4801 \\
Curtose & 4,2980 & 15,864 & 3,2452 & 4,1726 & 5,4687 & 2,2304 & 3,7775 & 3,0350 & 3,6295 \\
Observações & 27 & 27 & 27 & 27 & 27 & 27 & 27 & 27 & 27 \\
\hline
\end{tabular}

Fonte: Elaboração própria. 
Tabela 6 - Estatísticas descritivas (2009)

\begin{tabular}{l|lllllllll}
\hline Estatística & PIBpc & AGRO & IND & SERV & POP & ESP & EST & URB & TRIB \\
\hline Média & 7050,71 & $-0,016$ & $-0,010$ & 0,0398 & 0,0115 & 69,0296 & 6,6150 & 0,8217 & 0,0868 \\
Mediana & 6408,50 & $-0,025$ & 0,0443 & 0,0418 & 0,0097 & 69,4000 & 6,6783 & 0,8220 & 0,0859 \\
Variância & $1,88 \mathrm{e}+07$ & 0,0137 & 0,0142 & 0,0007 & $18 \mathrm{e}-6$ & 5,5737 & 1,2320 & 0,0066 & 0,0002 \\
Desvio Padrão & 4336,81 & 0,1174 & 0,1195 & 0,0278 & 0,0042 & 2,3608 & 1,1099 & 0,0815 & 0,0146 \\
Assimetria & 2,4481 & $-0,169$ & $-0,835$ & 0,1917 & 1,0875 & $-0,5000$ & 0,3934 & 0,1890 & 0,4535 \\
Curtose & 10,4331 & 2,9709 & 2,3006 & 2,3232 & 3,2607 & 2,4722 & 2,9468 & 2,0001 & 3,7669 \\
Observações & 27 & 27 & 27 & 27 & 27 & 27 & 27 & 27 & 27 \\
\hline
\end{tabular}

Fonte: Elaboração própria.

Recebido em: 22/04/2013.

Aceito em: 06/03/2014. 